\title{
Anchoring Schoolwide Positive Behavior Support in Structural School Reform
}

\author{
Wayne Sailor, Nina Zuna, Jeong-Hoon Choi, Jamie Thomas, and Amy McCart \\ University of Kansas \\ Blair Roger \\ Oakland, California
}

Schoolwide positive behavior support (SWPBS) exemplifies a longitudinal research program originating in the fields of special education and school psychology that has produced an extensive national database encompassing an evidence-based set of practices applicable to general education as well as special education students including those with severe disabilities. Schoolwide applications of evidence-based practices, however, are at some risk of falling victim to the ongoing bifurcation of education into the general and special education parallel and often noninteractive, professional systems of instruction. One potential solution to bifurcated practice is to embed (or contextualize) SWPBS in a broader, universal school reform agenda that coordinates and evaluates all educational intervention services and supports for the benefit of all students. A structural school reform process called the Schoolwide Applications Model (SAM) is described, which includes SWPBS as 1 of 15 critical features. Results from a 3-year, ongoing research project in a low-income, multicultural, urban school district in Northern California suggests that SWPBS, with its three levels of student support, guided by teams of general as well as special educators, can be an important contributor to academic as well as social achievement among students with and without disabilities and, as grounded within systematic school reform, can help to mitigate against the bifurcation of general and special education practices.

DESCRIPTORS: schoolwide positive behavior support, school reform, severe disabilities

Wayne Sailor is a professor in the Department of Special Education and an associate director in the Beach Center on Disability at the University of Kansas. The preparation of this article was supported in part by the Office of Special Education Programs (OSEP) Technical Assistance Center on Positive Behavior Interventions and Supports, Grant H326S030002, from the U.S. Department of Education. No endorsement from USDE or any supporting agency for this content should be inferred. The authors wish to thank the administrators, teachers, staff, students, and families of the Ravenswood City School District, East Palo Alto, California, for their contributions to the research reported here.

Address all correspondence and reprint requests to Wayne Sailor, 1200 Sunnyside, 3136 Haworth, University of Kansas, Lawrence, KS 66045. Email: wsailor@ku.edu
Managing challenging behavior and disciplining students in school environments consistently rank as the top concern among educators, parents, and policy makers (Public Agenda, 2004). In a recent Public Agenda (2004) report, more than $75 \%$ of teachers stated that "there are persistent troublemakers in their school who should have been removed from regular classrooms" (p. 1). Eighty-five percent of teachers felt that new teachers were inadequately prepared to deal with behavioral concerns. Seventy percent of teachers felt that zero tolerance polices were a very effective solution to deal with serious violations, and $65 \%$ of teachers thought holding parents responsible for student misbehavior was also effective.

The National Center for Education Statistics reports a downward trend in violent crimes; however, incidents affecting school climate still occurred on a frequent basis according to a recent survey (DeVoe, Peter, Noonan, Snyder, \& Baum, 2005). In fact, $29 \%$ of respondents reported school bullying occurred on a daily or weekly basis; $19 \%$ reported weekly disrespect to teachers and $13 \%$ indicated that teacher verbal abuse occurred on a weekly basis; and $71 \%$ of schools reported at least one or more violent incidents had occurred in the previous year, per each school site (DeVoe et al., 2005).

The Government Accounting Office (GAO, 2003) reported that 91,000 special education students $(1.4 \%$ of all special education students) were disciplined in 2002 by being removed from their educational setting. Two of the most frequent punishments for students were inschool suspension rooms or out-of-school suspensions resulting in home placement. Despite evidence indicating that suspension is ineffective for remediating challenging behavior (Mendez \& Knoff, 2003) and evidence of its negative impact on student progress (Troyan, 2003), suspension still remains a frequent choice among educators (Coleman, 2001).

Collectively, the reports cited above suggest that a majority of teachers reflect practices and favor policies suggestive of a critical need for a unified (general and special education) approach to school disciplinary responses to problem behavior on the part of students. There would also appear to be a need to explore ways 
that schools might be structured holistically to meet the diverse needs of all students with a set of common practices (cf. Burrello, Hoffman, \& Murray, 2005).

\section{The Emerging Importance of Whole-School Interventions}

Many schools have begun to implement alternative discipline programs that incorporate skill-building techniques such as self-management, problem solving, and conflict resolution (Norris, 2003; Skiba \& Peterson, 2003 ) and the use of positive adult role models (Rollins Kaiser-Urley, Potts, \& Creason, 2003) to improve student behavior and school climate. Skiba and Peterson (2003) provided data from several pilot schools implementing the Office of Special Education Programs' (OSEP)-funded Safe and Responsible Schools project. Some programmatic components within this project include bullying prevention, mentoring, civility curriculum, and conflict resolution. The results from these pilot schools indicated that effective instruction and the teaching of prosocial behaviors resulted in a $40-60 \%$ reduction in suspensions. Norris (2003) utilized a social and emotional curriculum to teach general as well as special education students self-regulation, self-management, and social skills. This author reported that many positive changes occurred in school climate and culture over a 3-year period, including better classroom management through teachers' use of established behavioral rules and expectations, reductions in fights during recess through a student strategy called "keep calm," and increased conflict resolution on school grounds through students' use of a "problemsolving diary."

Increasingly, school administrators have begun to understand the importance of developing a sense of community within their schools to encourage prosocial behavior on the part of all students. Through the use of before and after-school programs, which included campus clubs and tutoring programs, Van Zant and Martuccci (2002) established what visitors describe as an "energetic, yet relaxed positive" climate within their school (p. 34). As a result of these programs, the authors, a school principal and a before and after-school coordinator, reported dramatic decreases in office referrals, increased school attendance and parental involvement, and increased academic achievement as measured by math and literacy scores, which they attributed in part to the school climate interventions.

It has been well established that school climate is related to academic achievement (Joyce, Weil, \& Calhoun, 1996; Ma \& Klinger, 2000; Van Zant \& Martucci, 2002) In examining student and school variables on academic achievement, $\mathrm{Ma}$ and Klinger (2000) provided intriguing results. One of the explanatory variables in their analysis was school climate, which included three subscales measuring disciplinary climate, student academic expecta- tions, and parental involvement. These researchers found both disciplinary climate and student academic expectations to be significant predictors of math, science, and writing achievement. For writing achievement, both disciplinary climate and academic outcomes were significant over and above student variables. Of the three school climate variables, disciplinary climate was found to be the most important determinant of academic achievement. Whereas much of this research has been focused on the general education population, there is a growing body of evidence accruing regarding the effects of school climate on students with disabilities.

\section{Schoolwide Positive Behavior Support as an Example of Whole-School Intervention}

Schoolwide positive behavior support (SWPBS) is a term that is increasingly used to refer to levels or systems of positive interventions that are carried out in schools. SWPBS is an evidence-based set of interventions emerging from the fields of special education and school psychology that has demonstrated efficacy for applications to general as well as special education students including those with severe disabilities. SWPBS specifically addresses school climate as well as problem behavior. SWPBS follows a risk prevention logic and operates at three levels: Level 1, universal, providing intervention to the entire student body; Level 2, group, supporting children at the classroom level or utilizing small group instruction for students who have similar needs; and Level 3, individual, providing intensive behavioral intervention through an individualized support plan (Horner, Sugai, Todd, \& Lewis-Palmer, 2005). Whereas including all disciplines in developing a schoolwide plan is important, much of the PBS literature focuses on the discrete application of behavioral interventions for individual students. Further, the collaborative development and implementation of behavioral interventions are additionally limited, by often including only the behavioral consultant (i.e., university or district consultant) and the cooperating teacher rather than by utilizing a schoolwide PBS team as recommended based on controlled studies (i.e., Luiselli, Putnam, \& Handler, 2005). Only a handful of systemwide, research-validated approaches addressing problem behavior operate within whole schools (Horner et al., 2005; Luiselli et al., 2005; Sailor \& Roger, 2005). Chandler and Dahlquist (2002) suggested that developing and implementing appropriate behavioral interventions is the responsibility of all who work and interact with students engaging in problem behavior, again emphasizing the importance of team-based approaches to address behavioral issues.

The emerging issue of relevance for a holistic approach to discipline for all children in a school is how to fully integrate the three levels of SWPBS given the longer history of individual support being provided 
primarily by special educators with the shorter history of group and universal applications, being more identified with general education research and praxis. There are significant implications for students with extensive support needs (i.e., severe disabilities). A fully integrated and team-driven system of SWPBS application at all levels will be more likely to facilitate inclusive educational practices for these students than if they are the sole responsibility of special education.

Response to intervention (RTI) represents another emerging evidence-based practice that utilizes interdisciplinary teams to integrate special and general education practices focused on students at risk for special education (cf. Fuchs \& Fuchs, 2005). RTI primarily is an academic rather than behavioral intervention used to assist in the identification of services and support for students with learning difficulties. Similar to SWPBS procedures, RTI, as outlined by Fuchs and Fuchs (2005), utilizes a tiered series of increasing academic support at three levels: classroom support/modification, small group instruction, and intensive individualized support. In RTI, the student is monitored at each level and a student's movement to more intensive support is determined by academic response to the intervention. If none of the interventions are successful, a recommendation is made for a comprehensive evaluation for special education services. Finally, a key shared component of the RTI model and SWPBS is team led, data-based decision making. In fact, McMaster, Fuchs, Fuchs, and Compton (2005) suggested that more research is necessary to understand how other child variables (e.g., attention, motivation, and behavior) might impact responsiveness to academic intervention. Clearly, these authors intimated that no one intervention can address the multitude of variables contributing to successful child outcomes. The conceptual similarity of these two models (SWPBS and RTI) lends itself well to jointly addressing the academic and behavioral needs of children to ensure greater access to general education curriculum and increased inclusion within all general education settings. As such, it contributes to the integration of general and special education practices.

Furthermore, it is essential that the field address the universal application of new practices and models, such as RTI, and not relegate their use within a narrowly defined population, such as learning disabilities. The conceptual framework of RTI lends itself well to assessing students with varying levels of support needs. Measuring how well a child responds to an intervention and making programmatic decisions based upon these data is applicable to all students and suggests the importance of the use of a universal design for educational praxis. A next step that school reform researchers will need to examine is how schools can be restructured to facilitate the integration of general and special education practices.
Currently, many SWPBS teams are integrated within schools' prereferral teams (e.g., student support teamSST, student intervention team-SIT), thus making feasible the joint application of SWPBS and effective evidence-based interventions. The collaborative melding of SWPBS and a structured academic intervention such as RTI holds great promise for holistically addressing academic, social, emotional, and behavioral concerns of all students including those with the most severe disabilities. Recently, Horner et al. (2005) posited the importance of implementing dual academic and social interventions to achieve effective educational outcomes. They further stated that social skills instruction without appropriate academic instruction will not result in learning, nor is a chaotic classroom conducive to academic achievement.

Understanding the explicit impact of SWPBS on academic behavior represents the next frontier of SWPBS research and, as mentioned earlier, extends an opportunity to form new collaborative relationships among general and special educators to holistically address the needs of all students. However, only a few studies have so far linked SWPBS to academic gains (Horner et al., 2005; Lassen, Steele, \& Rios, 2005; Luiselli et al., 2005; Nelson, Martella, \& Marchand-Martella, 2002).

Horner et al. (2005) provided a brief review of research that examined the impact of SWPBS interventions on academics. Specifically, they reviewed research that found an inverse relationship between aggression as well as attention deficit/hyperactivity symptoms and academic gains. They reported, for example, that reading interventions implemented within a behaviorally chaotic classroom did not produce academic gains in reading performance. Further, only when SWPBS was a component within the reading interventions did improvement in reading scores occur. Finally, Horner et al. reported that schools that implemented both academic (a phonics-based reading program) and behavior support (SWPBS) achieved higher changes in percentages of students meeting state standards in reading assessment than schools that did not adopt SWPBS in conjunction with academic interventions (Horner et al., 2005). Horner et al. suggested that "...combining behavior support and effective instruction may be an important theme for school reform in the United States" (p. 382).

Lassen et al. (2005) and Lassen, Steele, and Sailor (in press) implemented all three levels of schoolwide PBS (universal, group, and individual) in one inner-city middle school over a 3-year period. These authors reported statistically significant decreases in office referrals and long-term suspensions across the 3 years. Additionally, they found that the decreases in office referrals and long-term suspensions were significant predictors of improved standardized math and reading scores.

Luiselli et al. (2005) implemented a whole-school behavioral model in one urban elementary school. Their 
intervention utilized a model known as Positive Schools (Putnam, Handler, \& Luiselli, 2003), in addition to teacher training on classroom instruction and behavior management. Their results indicated appreciable decreases in office disciplinary referrals (ODRs) for all students; however, inconsistent results were reported for suspension data. Despite the inconsistent findings for suspensions, both math and reading comprehension improved by $18 \%$ and $25 \%$, respectively.

Finally, Nelson et al. (2002) applied SWPBS in seven elementary schools over a 2 -year period. A standardized test with subtests on content areas such as math and reading was administered to all fourth graders in the district each year of the research study. Compared to the 28 elementary schools where SWPBS was not in place, researchers found statistically significant differences in the mean percentile gain scores of participating schools on all subtests except math.

Movement toward addressing both the academic and behavioral concerns of students at all three school levels (e.g., universal, group, and individual) represents an emerging practice in achieving high academic outcomes for all students. Additionally, given that both academic and behavioral interventions are necessary to achieve effective educational outcomes, the application of lully integrated models such as RTI and SWPBS represents new ways to meet the diverse academic and social needs of students including those with severe disabilities. Common elements that can be identified across many of these powerful evidence-based interventions are creating a major interest in strategies to unify educational processes within the field of educational administration (e.g., Burrello et al., 2005). Finally, a large and growing body of research clearly points to the need for schools to begin to operate as fully integrated systems (Banks et al., 2005).

\section{SWPBS and Educational Bifurcation?}

If SWPBS enhances student performance as reflected in scores on standardized tests of achievement, as available evidence thus far suggests, then an incentive exists to include students identified for special education supports and services in general education classrooms and other integrated school settings, with greater access to universal instructional strategies. A critical mediating factor, however, will be the extent to which students in special education are engaging in the general curriculum through their classroom participation. As increasing numbers of schools and school districts respond to federal pressure to include special education students in the general assessments, engagement with the general curriculum will become a critical factor in helping to ensure that schools can meet the requirements for demonstrating annual yearly progress (AYP).

If SWPBS falls victim to bifurcation, in that only general educators primarily guide Level 1 (universal) applications and only special educators primarily guide Level 2 (group) and Level 3 (individual support) applications, then an opportunity to enhance the probability of meeting AYP by linking SWPBS to inclusive practices will have been missed. To investigate the actual state of SWPBS practices as inferred from published reports, we reviewed and analyzed 185 articles from the Journal of Positive Behavior Interventions (JPBI), a primary source of research reports on positive behavior support interventions, to determine the level of application of the behavioral interventions reported. ${ }^{1}$

This review process began with the first issue of $J P B I$ in 1999 and concluded with volume 7, number 4, in 2005. Of the 185 articles examined, a total of 107 articles employed practical positive behavior support intervention strategies to improve the challenging behaviors of children or adults. Of the 107 articles, 55 reported interventions conducted in schools. Of the 55 reported investigations conducted in schools, 37 of these were individual support applications (about $67 \%$ ). Sixteen of the reported studies were universal applications (about $29 \%$ ) and only two studies reported a group application. Of the 37 individual intervention studies, 30 were focused on special education students (about $81 \%$ ). Only three studies reported individual support applications for general education students, with an additional four studies investigating individual applications to both general and special education students. Finally, $57 \%$ of the individual applications were delivered in separate special education settings where it might be reasonable to infer that grade-level participation in the general curriculum was minimal and general education teacher participation in the intervention was absent or minimal.

This review of published studies found no data on academic enhancements resulting from individual applications in which special education students were the participants. Furthermore, most of the universal interventions appeared, from the descriptions in the article, to be driven by general education whereas virtually all of the individual support reports were associated with special education. Level 2 interventions (group applications of SWPBS) seem to have generated little interest by either group, at least as evidenced from $J P B I$ published investigations. Although nothing substantive can be concluded from a cursory review of studies published over a 5-year period in a single scientific journal, and especially considering that individual applications have a much larger research history than universal applications of positive behavior support, there is nonetheless suggestive evidence for ongoing potential bifurcation of educational (general and special) interventions using SWPBS. To address this issue and

\footnotetext{
'This review was informal; that is, it was performed by one of the authors (J.-H.C.) without an estimate of interrater agreement provided by an independent reviewer.
} 
to best utilize the diverse talents of both general and special educators, a more integrated system for application will need to emerge. One potential design for ensuring a fully integrated management of SWPBS is to anchor the process in a broader context of school reform, particularly where the school reform agenda is driven by general education and focused on and evaluated by ongoing progress measurement from both academic and social indicators. In the next sections, we describe a particular system of school reform called the Schoolwide Applications Model (SAM) and present some descriptive (nonexperimental) data from its application in an inner-city, multicultural school district.

\section{Structured School Reform as a Solution to Educational Bifurcation}

SAM, as a particular example of structural school reform, emerged from a decade of ongoing research in the Kansas City, Kansas School District (USD 500), in an effort to combine successful operations in participating school sites implementing inclusive education (McCart, 2003; McCart \& Englebrick, 2005), SWPBS (Utley \& Sailor, 2002); urban, multicultural applications (Obiakor \& Utley, 2003); and site-based, datareferenced decision making (Lawson \& Sailor, 2000; Sailor \& McCart, 2004).

SAM has 6 "guiding principles" and 15 "critical features" that are nested within each of the guiding principles (see Table 1). The conceptual framework for the model is described in detail in the video Creating a Unified System: Integrating General and Special Education for the Benefit of All Students (Sailor \& McCart, 2004) and in Sailor and Roger (2005). Each of the 15 features can be evaluated for each participating school, with repeated measures over time using the Schoolwide Applications Model Analysis System (SAMAN), an assessment tool that is presently used to estimate fidelity of implementation of the model within and across schools over time (Sailor \& Roger, 2003). Each of the 15 critical features is evaluated using a Likert scale from 0 to 3 , where 0 reflects essentially no manifestation of the feature at the school and 3 represents full implementation. The assessment typically requires about one to two school days to complete, which includes sources of data from interviews with administrators, school staff, parents, and others, as well as record reviews and observations of students and teachers in different settings.

SAMAN assessments were conducted at two schools in 2004 by two independent assessors with $73 \%$ interrater agreement (sum of agreements and disagreements over each of the 15 critical features of SAM divided by 100 for each assessment). SAMAN assessments at four schools in 2005 yielded an average interrater agreement of $87 \%$. Although six sets of observations are too few to provide substantive psychometrics, interrater agreement on SAMAN assessments conducted thus far
Table 1

Six Guiding Principles and Their Corresponding Critical Features

1. General education guides all instruction

CF1: All students are served at the school in which they would be served if they had no need for special services or supports

CF2: All students at school are considered general education students

CF3: General education teachers assume primary responsibility for all students at the school

2. All school resources are configured to benefit all students

CF4: School is inclusive of all students for all school functions

CF5: School is organized to provide all specialized support, adaptations, and accommodations to students in such a way as to maximize the number of students who will benefit

CF6: All students are taught in accordance with the general curriculum with accommodations, adaptation supports, and services as needed

3. School proactively addresses social development and citizenship

CF7: The school has an active SWPBS program

4. School is a democratically organized, data-driven, problem-solving system

CF8: The school is a data-driven, collaborative, decision-making, learning organization with all major functions guided by team processes

CF9: School effectively incorporates general education students in the instructional process

CF10: All personnel at the school participate in the teaching/learning process and are valued for their respective contributions to pupil academic and social outcomes

CF11: School personnel use a uniform, noncategorical lexicon to describe both personnel and teaching/ learning functions

CF12: School has established an SLT empowered by the school and the district to implement SAM at the school

5. School has open boundaries in relation to its families and its community

CF13: School has working partnership with families of students who attend the school

CF14: School has working partnership with its community business and service providers

6. School enjoys district support for undertaking extensive systems change

CF15: SAM implementation at the school site is fully recognized and supported by the district

indicates a promising trend toward reliable measurement of SAM processes, thus enabling reliable estimates of the fidelity of implementation of the entire school reform system (average score for the 15 critical features, each assessment) as well as for each individual feature.

\section{SAM and SWPBS}

As shown in Table 1, SWPBS is Critical Feature 7, listed under guiding principle 3 , in the SAM. Table 2 shows how this feature is defined and scored and the sources of data used to determine the score (Sailor \& Roger, 2003). SAMAN scoring on this feature is as 
Table 2

SAMAN Critical Feature 7

\begin{tabular}{|c|c|c|c|}
\hline Feature & Assessment & Source & Score (circle one) \\
\hline $\begin{array}{l}\text { 7. The school has an active SWPBS } \\
\text { program operating at all } 3 \text { levels }\end{array}$ & $\begin{array}{l}\text { - Extent of SWPBS practices } \\
\text { Behavior Support (SWPBS) Practices } \\
\text { - Extent of SWPBS training in school } \\
\text { - Extent of ODR data tracking to } \\
\text { reflect SWPBS outcomes }\end{array}$ & $\begin{array}{l}\text { - SWPBS coach } \\
\text { - ODR database } \\
\text { - SWPBS support } \\
\text { - Plan reviews } \\
\text { - Observations of SWPBS } \\
\text { implementation at } \\
\text { three levels }\end{array}$ & $\begin{array}{llll}0 & 1 & 2 & 3\end{array}$ \\
\hline
\end{tabular}

Note. ODR = office disciplinary referral; SAMAN = Schoolwide Applications Model Analysis System; SWPBS = schoolwide positive behavior support.

follows: $0=$ SWPBS training has not occurred and/or SWPBS is not operational at the school; $1=$ some SWPBS training has occurred involving some school staff, and some SWPBS is operational at one or two levels; 2 = extensive SWPBS training has occurred involving most staff (including teachers) and SWPBS is operational at one or two levels; $3=$ school is fully trained and SWPBS is operational at all three levels with systematic tracking of at least schoolwide ODR data. Sources of data specified in the SAMAN manual for this feature are as follows: identify and interview school SWPBS facilitator ("coach"); examine school databases for SWPBS outcomes and processes; examine sample of individual SWPBS support plans; and observe implementation of SWPBS at each level. Note that to earn a maximum score of 3 on Critical Feature 7 , positive behavior support must be operational at all three levels.

Schools seeking to make progress on their implementation of SAM must utilize professional development and participate in ongoing technical assistance in SWPBS, and do so within a fully integrated context that is driven by general education. An important consideration in this contextualization of SWPBS is that both general and special educators become proficient in application of all three levels of SWPBS. In other words, it is our hypothesis that contextualizing SWPBS within broader school reform, in this case SAM, will mitigate against a tendency within schools to bifurcate the SWPBS process, wherein individual level applications become strictly the purview of special education.

A first step in SAM implementation includes schools and district administrators putting into place some structural requirements. Because $\mathrm{SAM}$ is a fully integrated and unified approach for education of all students, specific procedures are needed to maintain this philosophy. These procedures ensure that schools will engage in collaborative, team-driven decision making directed to specific interventions, professional development activities, curricular innovations, and so forth, with a high probability, based on available scientific evidence, of improving academic and social outcomes for all students. The required structural elements at the school level are (1) formation and regularly scheduled meetings of a site leadership team (SLT), chaired by the building principal; and (2) an ongoing operational plan for the school called the SAM Action Plan, which is developed through a full-day retreat by the SLT, called school-centered planning (SCP), and which is facilitated by a SAM technical assistance consultant. This "retreat" takes place twice per year, once at the outset of the fall term, usually in August and again in January prior to start-up of the spring term. The SLT, usually consisting of six to eight teachers, general education as well as special education, English language learner (ELL) teachers, and others, is chaired by the principal, meets regularly, considers data on student social and academic progress, and generally guides school-level interventions consistent with a school-based, decision-making model. The action plan specifies discrete steps to be undertaken each term at the school to implement the systems change processes required to instantiate $S A M$.

The required structural additions at the district level include two processes. The first is an administrative team called the district leadership team (DLT). This team manages the special policy considerations related to the systemic change processes within SAM schools. The second addition is a resource management team called the district resource team (DRT). This team, chaired by an assistant superintendent is organized to deal with specific resource requests from SAM site principals. The DRT receives written requests from principals for specific district-level supports that the SLT has concluded are needed to implement the sites' action plan. These requests typically deal with such issues as personnel requests, professional development activities, or the use of consultants for specific training needs. Following the DRT meeting, a written recommendation is forwarded from the DRT to the DLT for discussion. At this final meeting, the recommendation from the DRT is approved, disapproved, or modified, and the requesting principal is notified of the decision.

\section{Preliminary Results from an Urban-Core School District}

The SAM school reform approach was begun in the Ravenswood City School District, East Palo Alto, 
California, in the 2002-2003 academic year (Sailor \& Roger, 2005). Ravenswood serves about 4500 students, $94 \%$ of whom qualify for free and reduced lunches. This model has been moving to scale in all 12 Ravenswood schools, including pre-K, $\mathrm{K}-3, \mathrm{~K}-4$, and 5-8 school grade configurations from 2002 to 2005 . Ravenswood is classified in California as an elementary district and therefore does not operate a high school. Presented next are implications for SWPBS based on data resulting from the implementation of SAM in the first four ("Cohort 1") of 12 Ravenswood schools, currently in the third year of ongoing technical assistance and training on the process. Table 3 illustrates demographic data on each of the Cohort 1 schools.

To illustrate the SAM interactive process between individual school sites and the district central office, consider the experience of School C, one of the four Cohort 1 schools in Ravenswood. School C began the 2002-2003 academic year with several special education, self-contained classes. A priority for the first action plan at this site was devoted to eliminating selfcontained classrooms and placing students with individual education plans (IEPs), including students with severe disabilities, in general education classrooms with participation in other integrated settings appropriate to each student's grade level consistent with SAM's guiding principles (Sailor \& Roger, 2005). Subsequent modifications to the action plan at School $\mathrm{C}$ were directed to professional development activities, staffing issues, space utilization (what to do for example, with the previous special education classrooms), and other supportive activities to improve the instructional process under the new inclusive model.

In Ravenswood, the DLT functions are subsumed within the superintendent's advisory council, which meets weekly and is comprised of the superintendent and his or her top administrative staff at the district level. School C, during the 2003-2004 school year, used the DRT process to move from a model utilizing heavy paraprofessional supports (a remnant of the previous special education classroom configuration) to a more collaborative general-special education teaching configuration to better implement SAM. Following a meeting of the SLT considering the next steps in implementing its action plan, the principal initiated a written request to the DRT chair to transfer three paraprofessionals to other locations in exchange for one support teacher (a special education teacher) to be transferred to School C. The district assistant superintendent who chaired the DRT convened a group of "stakeholders," including the principals of two other schools, to discuss the implications of School C's request. At this meeting, the request was approved for a positive recommendation to the DLT. The recommendation was added to the "SAM business" portion of the next superintendent's advisory committee (the "DLT" in SAM terms) where it was approved at this next level. The decision was placed in the minutes of the DLT meeting (archived) and the principal of School $\mathrm{C}$ was notified. All of the meetings utilized agendas to record the minutes that rendered the SAM process "transparent" to all stakeholders. Because schools often compete for scarce district resources, this process helps to build trust within the district as this complex school reform process moves to scale.

\section{Data-Based Decision Making and Some Preliminary Results}

A guiding principle of SAM involves an ongoing data processing and analysis interaction between the SAM sites and the SAM research lab in Kansas. The database for each participating school includes schoollevel assessments: grade-level curriculum-based measures (CBMs); positive behavior support measures from the schoolwide information system (SWIS) (May et al.,

Table 3

Demographics of Cohort 1 Schools in the Ravenswood City School District

\begin{tabular}{|c|c|c|c|}
\hline & School type (elementary/middle) & No. of students $(2004-2005)$ & Demographics \\
\hline School A & $\begin{array}{l}\text { Middle school } \\
\text { Grades 5-8 }\end{array}$ & 346 & $\begin{array}{l}82 \% \text { Latino } \\
8 \% \text { African American } \\
7 \% \text { Pacific Islander } \\
3 \% \text { Other (non-White) }\end{array}$ \\
\hline School B & $\begin{array}{l}\text { Middle school } \\
\text { Grades 5-8 }\end{array}$ & 514 & $\begin{array}{l}80 \% \text { Latino } \\
7 \% \text { African American } \\
10 \% \text { Pacific Islander } \\
3 \% \text { Other (non-White) }\end{array}$ \\
\hline School C & $\begin{array}{l}\text { Middle school } \\
\text { Grades 5-8 }\end{array}$ & 443 & $\begin{array}{l}68 \% \text { Latino } \\
\text { 17\% African American } \\
10 \% \text { Pacific Islander } \\
3 \% \text { Other (non-White) }\end{array}$ \\
\hline School D & $\begin{array}{l}\text { Elementary } \\
\text { Charter school } \\
\text { Grades K-3 }\end{array}$ & 456 & $\begin{array}{l}85 \% \text { Latino } \\
10 \% \text { African American } \\
3 \% \text { Pacific Islander } \\
2 \% \text { Other (non-White) }\end{array}$ \\
\hline
\end{tabular}




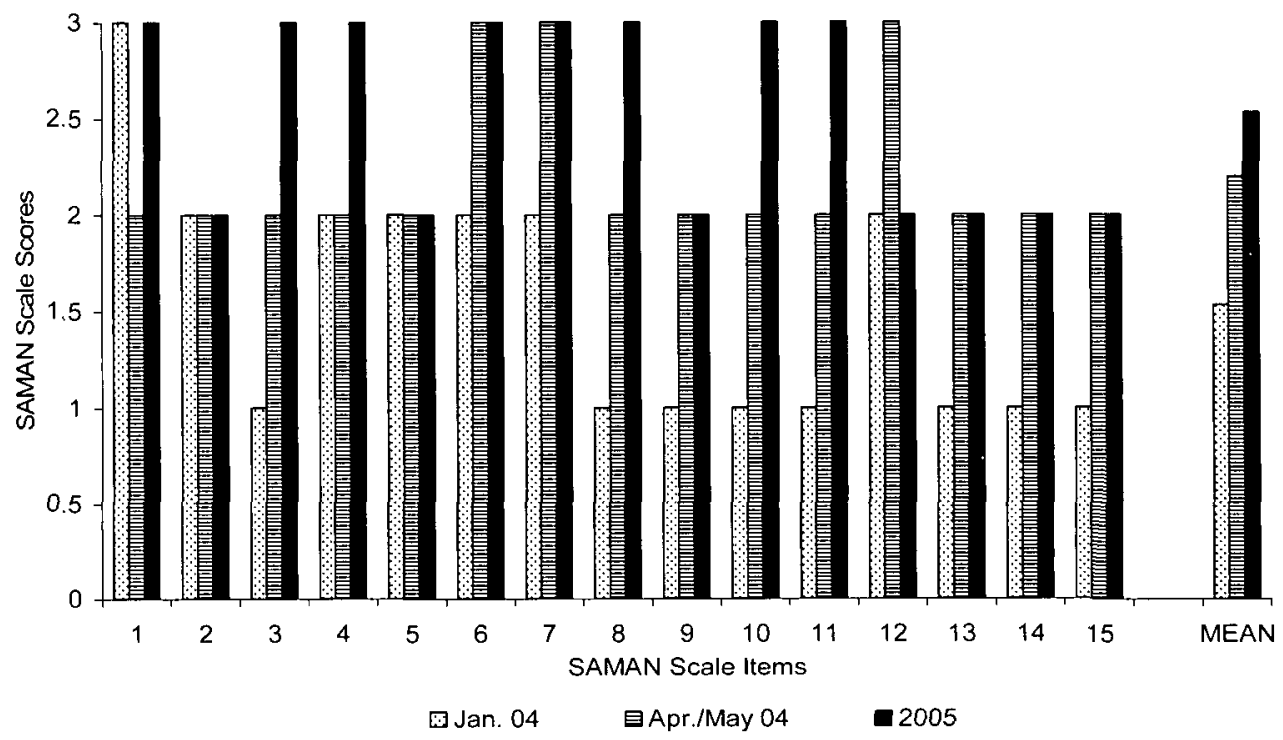

Figure 1. Schoolwide Applications Model Analysis System (SAMAN) critical feature progress in School B.

2000); and progress measures on IEP objectives for students whose disabilities prevent them from participating either in CBMs or in standardized yearly state assessments. Also included are measures of school climate; SAMAN biannual assessments; and district-level assessments, including standardized state assessments in math and literacy, tardiness, attendance, and measures of adaptive assessments for students with IEPS who do not participate in the general state assessments because of the severity of their disabilities.

These data are charted in the Kansas research laboratory for repeated measures estimates of progress over time for each school site, with statistical estimates of significance where appropriate, and are returned to each school site "data manager" for use in PowerPoint presentations at the SLT meetings. The school SLTs use these data to make decisions regarding specific interventions geared to their action plans to improve student academic and social progress at each grade level. $\mathrm{SAM}$, in this way, assists schools to make data-based decisions regarding specific consultations, professional development activities, and so forth rather than simply embracing "the next big thing."

To illustrate this process, we present data from School $B$ in the Ravenswood district for the second term of the 2004-2005 school year. Figure 1 presents the results of three consecutive SAMAN assessments for School B. Note that Critical Feature 7 measures progress on SWPBS at all three levels for the entire school. The results of these consecutive assessments on the SAM fidelity-of-implementation instrument SAMAN reflect steady progress on most critical features over about $21 / 2$ years of implementation. No data from 2003 appears because the instrument did not become available until January 2004. Schoolwide PBS (Critical Feature 7) was assessed as fully operational at School B from the spring of 2004 and forward. These data include all students and faculty in the school, and all three levels of SWPBS.

\section{SAM and Academic Progress for All Assessed Students}

Schools laboring under the accountability standards (i.e., AYP) of No Child Left Behind (NCLB) have as their primary interest the enhancement of academic progress of all assessed students as measured by standardized state grade-level achievement tests, particularly in math and literacy. ${ }^{2}$ If SAM, as a school reform process, had no appreciable effect on student achievement outcomes, there would be little incentive to undergo the rigorous systems change processes needed to put it into place. To enable the SLT at School B to estimate the efficacy of SAM implementation (all features) for student academic achievement, we conducted a preliminary regression analysis (Maxwell \& Delaney, 2004; Tabachnik \& Fidell, 2001) on two of the schools' sets of achievement test progress data over the 2003-2004 and 2004-2005 academic year (all grades).

\footnotetext{
${ }^{2}$ In Ravenswood, students with IEPs participate in the general assessments unless the extent of the student's disabilitics precludes participation (i.c., students with severe disabilities). Presently, about $20 \%$ of students with IEPs are exempt (about $2 \%$ of the total student body at any school). There are no currently satisfactory measures of academic progress for students with severe disabilities in California, by our judgment, so progress data for this population of students are not reported here. The state is reportedly developing a new adaptive assessment tool for use with this population, which is not yet available. The English test score changes that formed the basis for the regression analysis were thus sampled from all but approximately $2 \%$ of school students.
} 
The California English Language Development Test (CELDT) was the dependent variable measuring academic progress. The fidelity of SAM implementation was measured by the repeated SAMAN assessments. Figure 2 presents the results of the changes on the two measured variables over the 2-year period. Math score changes are included graphically, but regression data are only computed for English for purposes of illustration here. The visual results shown in Figure 2 for math score fluctuations over this period would appear to be obviously significant. We chose for this report to estimate the impact of SAM on the English test score changes because those results are less visually dramatic.

In the case of School B, a highly significant correlation was observed between the CELDT across all grades (shaded bar graphs in Figure 2), $M=516.83$, $S D=54.97, N=520$, and SAMAN mean scale scores over three assessments (line graph in Figure 2), $M=$ 2.03, $S D=0.5, r(518)=.286, p<.001$. The regression analysis for the observed data revealed that the average scores of the 15 critical features estimated from SAMAN scores over the change period serve as a significant predictor of the CELDT score improvement $(\beta=.286, p<.01)$, explaining about $8.2 \%$ of the variance. Although $8.2 \%$ of the variance may seem numerically small, in the regression analysis, which is concerned with factors that influence the slope of the lines of change, relatively small proportions of variance can indicate significant impacts. These results indicated that SAMAN change scores accounted for a significant amount of the improvement of all of the assessed students as reflected on the English achievement test results over the 2-year period.

Figures 3 and 4 illustrate a somewhat finer level of analysis that the School B SLT considered in its data- based decision process. Figure 3 presents grade-level data from School B on a curriculum-based measure (CBM) results across 3 years on English Language Arts, looking at the percentage of students at or above "proficient" on this measure. The SLT, based on this graphic, made specific recommendations to enhance performance growth at the sixth grade level. Figure 4 presents SWIS data on ODRs over a 2-year period, expressed as average referrals per day for the 4 months of the school year with the highest number of referrals. The SLT utilized these data to recommend a set of specific interventions and classroom supports to the school SWPBS core team directed to the action plan objective of reducing ODRs in November and December.

\section{The Specific Contribution of SWPBS as a Critical Feature of SAM to Academic Achievement}

The regression analysis for the School B database over a 2-year SAM implementation period suggests that SAM positively impacts academic achievement at School B as reflected in literacy scores (English Language Achievement Test). These data, as mentioned, include all but about $20 \%$ of students with IEPs at the school or about $2 \%$ of the schools' student body. Critical Feature 7, SWPBS, was also shown to be related to academic progress. To estimate this contribution, we examined the statistical relationship of SAMAN Item 7 SWPBS and academic achievement aggregated across three Cohort 1 middle schools (all grades) as measured by the California Standardized Test (CST), which combines math and English results. Data could not be obtained from the fourth Cohort 1 school because, as a charter school, the students did not participate in the CST assessments.

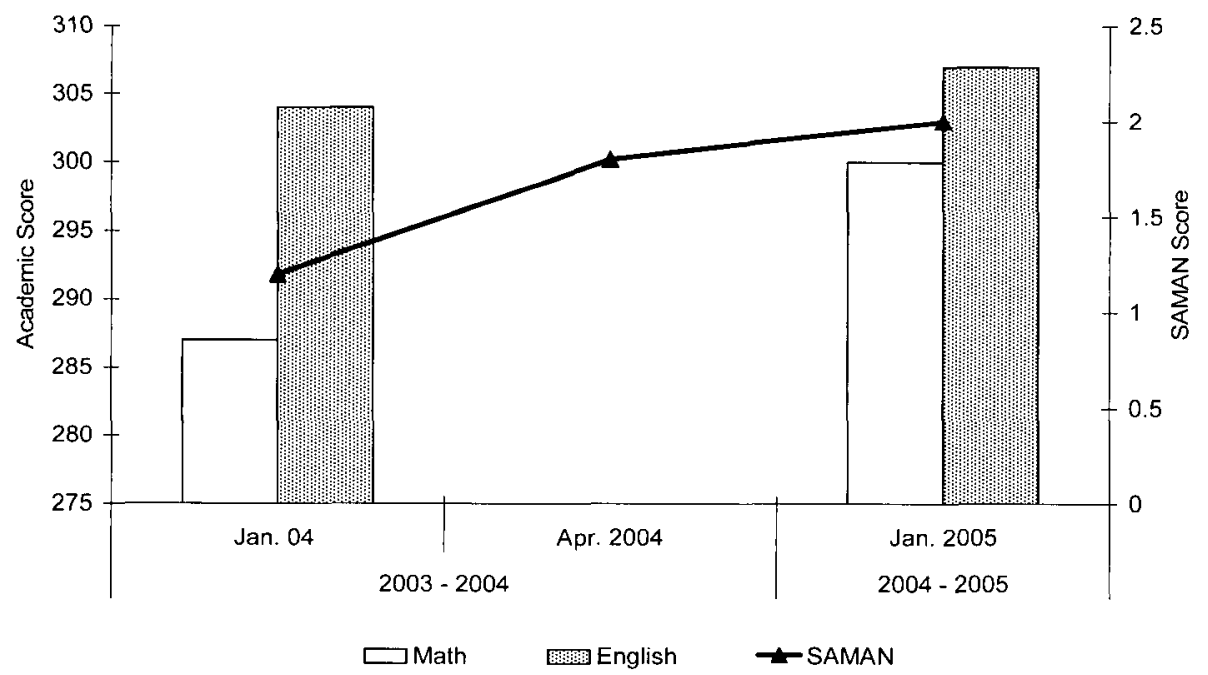

Figure 2. Schoolwide Applications Model Analysis System (SAMAN) and academic progress in School B. 


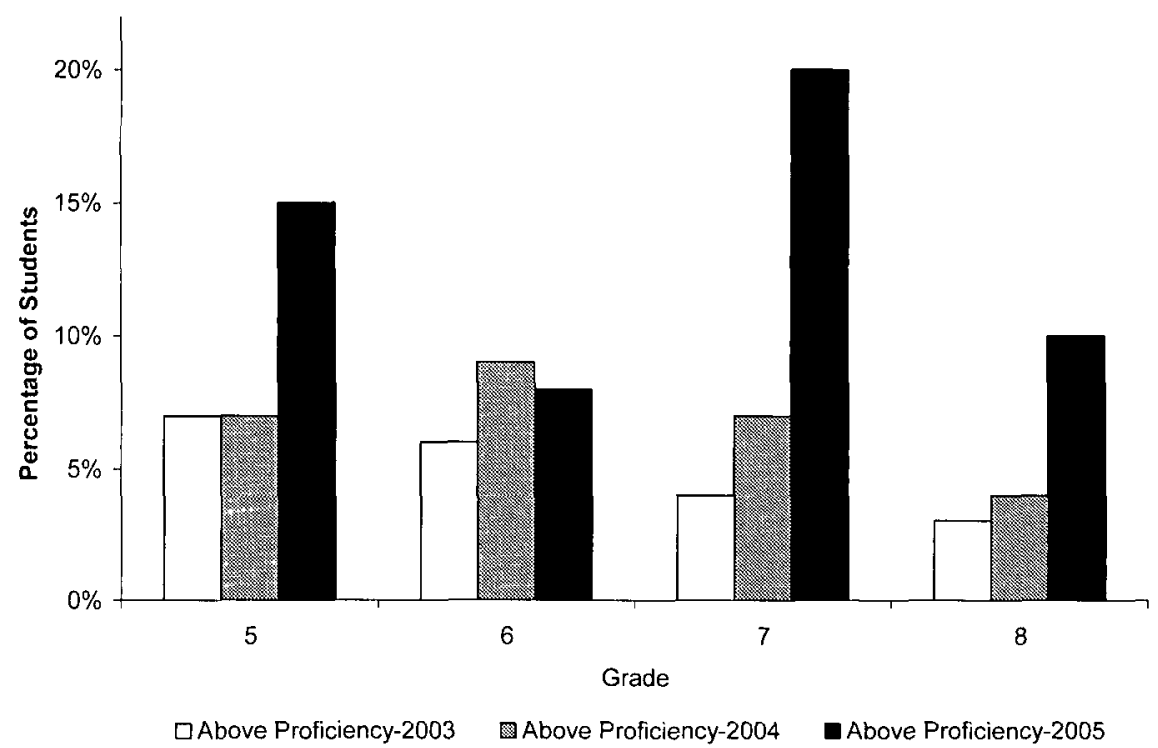

Figure 3. Changes of student percentage above proficiency level in English Language Arts.

Figure 5 presents the aggregate data from the three Cohort 1 schools that started SAM in the 2003-2004 school year. Results reflect a concurrent increase in students' CST scores with associated increases in SWPBS implementation, as measured by SAMAN, from the 2003-2004 school year to the 2004-2005 school year. For the analysis, the 2003 CST scores of 680 students who enrolled in the same schools for two successive years (i.e., 2003-2004 and 2004-2005 school years) were paired with 2004 CST sores. A paired sample $t$ test result showed that the CST scores significantly increased in 2004 school year, $t(679)=-7.535, p<.01$. In the meantime, the SWPBS status of the three elementary schools in the SAMAN assessment (Item 7 scores) increased from an average of 1.3 (range from 1 to 2 ) to 3 . Figure 5 illustrates the relationship between mean CST scores and SWPBS status across the academic year.

Regression analysis followed the $t$ test to examine the specific relationship between SWPBS status (Item 7) and CST scores for the three cohort schools. When a school factor (i.e., differences among the three schools) and Item 7 score served as independent variables, the school factor and the Item 7 score, in combination, were significantly associated with the CST scores, $R^{2}=.005$,

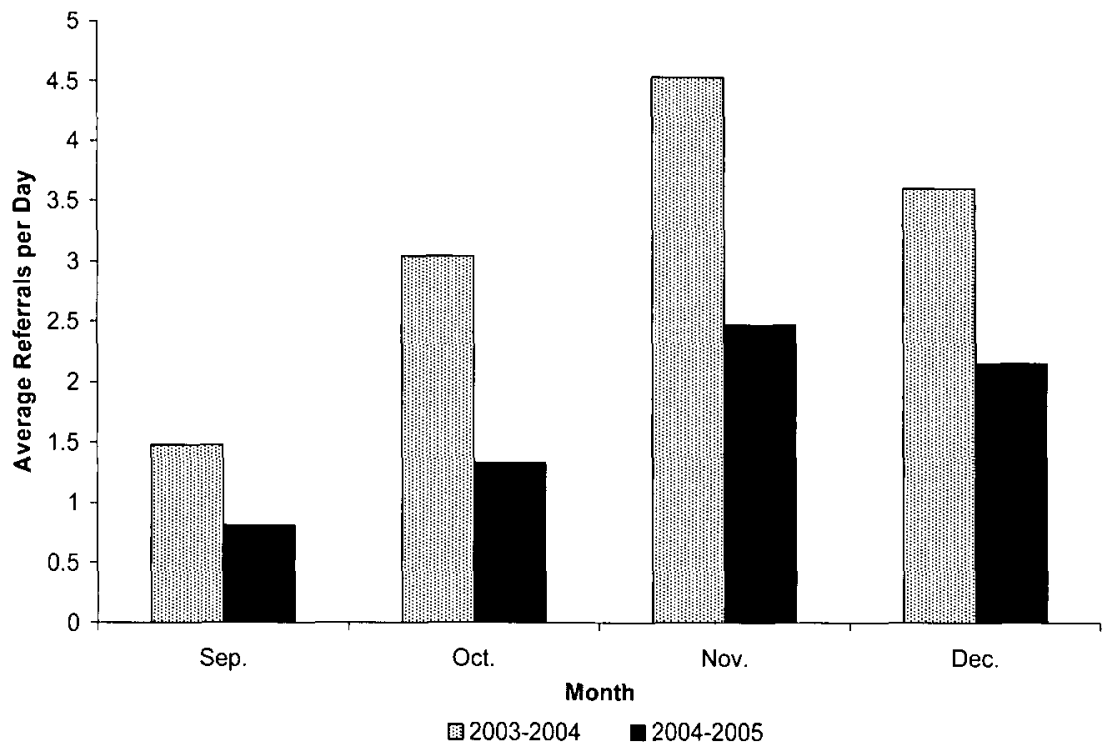

Figure 4. Reduction of office discipline referrals in School B. 


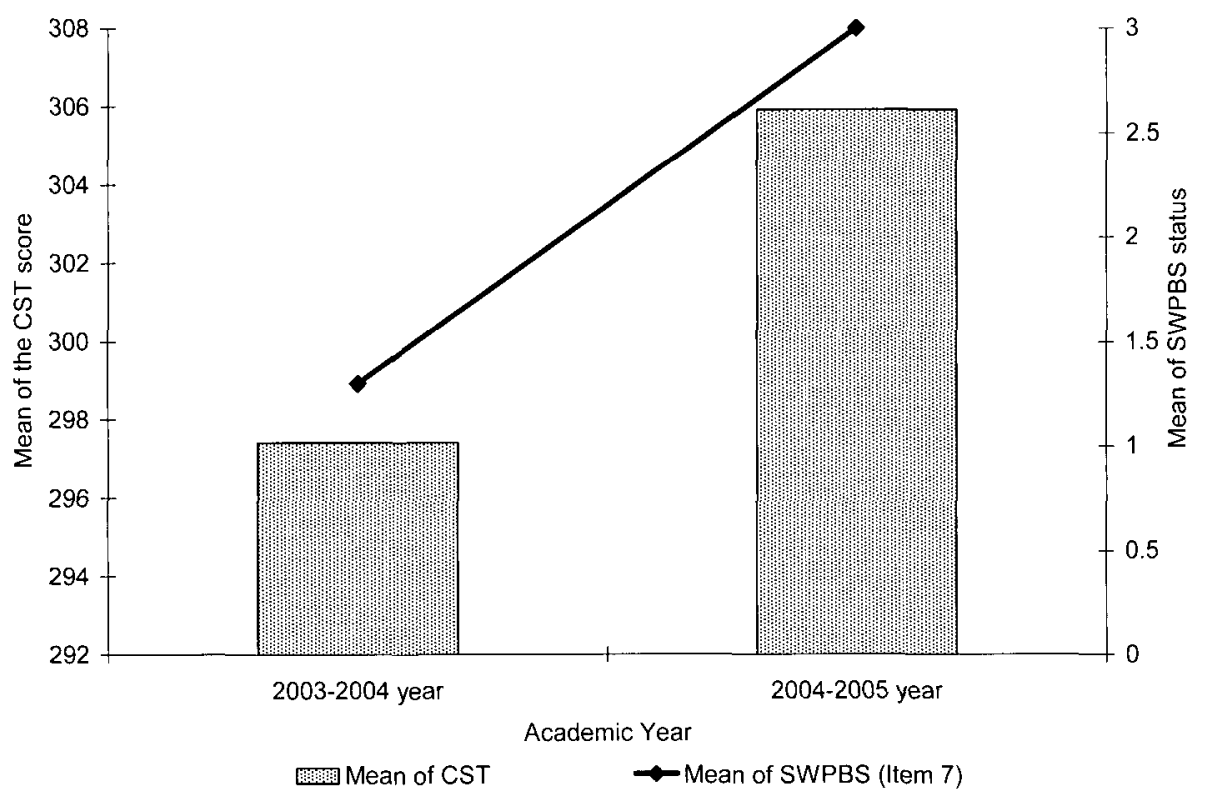

Figure 5. California Standardized Test (CST) scores and positive behavior support status improvement.

$F(2,1357)=3.67, p=.026$. Although this result indicates that Item 7 and the school factor, taken together, reliably predict CST scores, careful interpretation of the results is needed because the variation in the dependent variable (i.e., the CST scores) explained by the regressors (i.e., school factor and the Item 7 score) was not high $\left(0.5 \%\right.$ of the $R^{2}$ value). However, the SWPBS scale score as measured by SAMAN Item 7 had a significant positive relationship with the CST scores. According to the simple regression result based on the Pearson correlation, the SWPBS status was significantly correlated with the CST scores, $r=.073, p=.003$; however, the school factor was not significant, $r=.016$, $p=.281$. Detailed results of the multiple regression analysis also revealed that SWPBS status was a better predictor for the CST scores than the school factor. According to the standardized regression coefficients, the value of SAMAN Item 7 (.074) was higher than the school factor $(-.003)$. The unique proportion of variance contributed by the school factor alone to the CST score $(0.0004 \%)$ was not significant, $t(1357)=-0.092$, $p=927$. Alternately, SWPBS status contributed a significant proportion of variance to the CST score $(0.52 \%), t(1357)=2.646, p=.008$, which further substantiated the significant positive relationship between SWPBS status and CST scores. These findings indicate that SWPBS as measured by SAMAN Item 7 scale score changes provides a more powerful influence on overall academic performance gains (all assessed students, all three schools) than any influence that can simply be explained by particular differences between individual schools. After all, there is suggestive evidence that SWPBS status highly affected CST scores of the three cohort schools without distinguishing among the schools.

The correlation between the CST score change and SWPBS status (Item 7) in 2004 was also calculated to examine the impact of SWPBS status on CST score changes with two additional schools from Cohort 2 (SAM implementation begun in 2004), for a total of 881 students across six schools. All students included in the analysis were those enrolled in the same schools for the two successive school years (i.e., 2003-2004 and 2004-2005 school year). Each assessed student's CST score differences between 2003-2004 and 2004-2005 school years was calculated and paired with the SWPBS status in 2004-2005 school year. The results showed that the CST score difference was significantly and positively correlated with the SWPBS status based on the SAMAN Item 7 assessment, $r(879)=.229, p<.01$.

Collectively, these results suggest that higher levels of SWPBS implementation (i.e., operating at all three levels), including all students and faculty within a school, produce greater impact on at least one standardized measure of academic achievement. ${ }^{3}$ The SWPBS status (Item 7) of the Ravenswood schools has been developed within the context of SAM implementation. As a component of the structural school reform process, SAM, the SWPBS critical feature has a significant correlation with the total SAMAN score, $r(9)=.706$,

\footnotetext{
${ }^{3}$ Statistical results reported in this paper, although suggestive, must be regarded as tentative and as indicating a potential for educational gains rather than efficacy of SAM or any other intervention because no experimental design was employed in the Ravenswood sample.
} 
$p=.015$. This internal consistency measure further suggests that well-integrated application at all three levels of SWPBS within the SAM structural reform system can positively affect student academic performance.

\section{Summary and Conclusions}

In this paper, we have advocated for contextualizing SWPBS by integrating its three levels of support into a broader school reform agenda that effectively integrates and coordinates all services and supports at the school so that each can work for the benefit of all students. We included some suggestive evidence from a cursory review of published literature that SWPBS praxis is at some risk of falling victim to the ongoing educational bifurcation that occurs between special and general education. We expressed concern that the individual level of SWPBS support will become solely the responsibility of special educators and that group and universal supports will be identified solely with general educators. We provided an example of a school reform process called the SAM that effectively integrates SWPBS within a broader context that implements 14 critical features in addition to SWPBS. We provided descriptive evidence from SAM implementation in an urban-core school district in that SAM positively affects academic and social progress of all students, including those with disabilities, who participate in the general assessments (all but about $20 \%$ of the students with IEPs). Further, we provided descriptive evidence that SWPBS, as a single critical feature of SAM, has a significant positive impact on academic indicators, again for all assessed students, a finding which partially replicates similar findings reported in recent $S W P B S$ research reports. Because of the lack of reliable and valid student progress measures applicable to students with severe disabilities, who are exempt from participation in general assessments, we were unable to report effects of SAM (and SWPBS) on those students, although they are fully included for all educational processes in accordance with SAM. When teachers and school administrators are offered viable alternatives to zero tolerance policies, and when these alternatives have been shown to boost school climate, academic achievement, and social outcomes for students, overall educational gains are demonstrably noteworthy.

RTI, SWPBS, and other unified support programs ofler promising results, but special and general educators must collaborate within a common educational framework in our view if effective outcomes for students both with and without disabilities are the desired outcome. For example, linking general and special education supports is essential if we want to ensure that the students in special education are actively engaged in the general curriculum and can effectively participate in the general assessments. And, although more re- search is needed, by anchoring SWPBS in a broader context of school reform, as exemplified in the Ravenswood school district, there is suggestive evidence that academic gains for students both with and without disabilities can be achieved. When SAM is implemented, the contextualization of SWPBS for both general and special educators becomes a driving force and predictive indicator of change within schools. Finally, when general as well as special educators engage all three levels of SWPBS applications, the possibilities of teamdriven, collaborative instruction are enhanced. General education teachers, through this process, can learn innovative ways to individualize and differentiate instruction. Special education teachers learn to address the support needs of all students through integrated application of their specialized knowledge. Some limited evidence thus far suggests that educational unification, such as represented in the SAM process, holds potential for engaging all students in the general curriculum including those with severe disabilities, and except for that subpopulation, for reflecting progress as measured by standardized tests of grade level achievement.

\section{References}

Banks, J., Cochran-Smith, M., Moll, L., Richert, A., Zeichner, K., LePage, P., Darling-Hammond, L., Duffy, H., \& McDonald, M. (2005). Teaching diverse learners. In L. Darling-Hammond \& J. Bransford (Eds.) (pp. 232-274). Preparing teachers for a changing world. San Francisco, CA: Jossey-Bass.

Burrello, L., Hoffman, L., \& Murray, L. (2005). School leaders building capacity from within. Thousand Oaks, CA: Corwin Press.

Chandler, L. K., \& Dahlquist, C. M. (2002). Functional assessment: Strategies to prevent and remediate challenging behavior in school settings. Upper Saddle River: Prentice Hall.

Coleman, G. (2001). Issues in education: View from the other side of the room. Westport, CT: Bergin \& Carvey.

DeVoe, J. F., Peter, K., Noonan, M., Snyder, T. D., \& Baum, K. (2005). Indicators of school crime and safety: 2005 (NCES 2006-001/NCJ 210697). U.S. Departments of Education and Justice. Washington, DC: U.S. Government; Education Commission of the States (2002). Zero tolerance. Retrieved on November 29, 2005, from http://www.ecs.org.

Fuchs, D., \& Fuchs, L. S. (2005). Responsiveness to intervention: A blueprint for practitioners, policymakers and parents. Teaching Exceptional Children, 38, 57-61.

Government Accounting Office. (2003). Special education: Clearer guidance would enhance implementation of federal disciplinary provisions. (Publication No. 03-550). Washington, DC: Author.

Horner, R. H., Sugai, G., Todd, A. W., \& Lewis-Palmer, T. (2005). School-wide positive behavior support: An alternative approach to discipline in schools. In L. Bambara \& L. Kern (Eds.), Positive behavior support (pp. 359-390). New York: Guilford Press.

Joyce, B. R., Weil, M., \& Calhoun, E. (1996). Models of teaching. Boston, MA: Allyn Bacon.

Lassen, S. R., Steele, M. M., \& Rios, J. (2005). The impact of PBS on academic achievement indicators in an inner-city middle school. Poster presented at the 2nd International Conference on Positive Behavior Support, Tampa, FL. 
Lassen, S., Steele, M., \& Sailor, W. (in press). The relationship of school-wide positive behavior support to academic achievement in an urban middle school. School Psychology Review.

Lawson, H., \& Sailor, W. (2000). Integrating services, collaborating, and developing connections with schools. Focus on Exceptional Children, 33, 1-22.

Luiselli, J. K., Putnam, R. F., \& Handler, M. W. (2005). Wholeschool behavior support: Effects on student discipline problems and academic performance. Educational Psychology, 25, 183-198.

Ma, X., \& Klinger, D. A. (2000). Hierarchical linear modeling of student and school effects on academic achievement. Canadian Journal of Education, 25, 41-55.

Maxwell, S. E., \& Delaney, H. D. (2004). Designing experiments and analyzing data: A model comparison approach (2nd ed.). Belmont, CA: Wadsworth.

May, S., Ard, W., III, Todd, A. W., Horner, R. H., Glasgow, A., \& Sugai, G. (2000). School-wide information system. Eugene: Educational and community supports, University of Oregon.

McCart, A. (2003). Effectiveness of school-wide positive behavior support in two urban schools. Unpublished dissertation. University of Kansas.

McCart, A., \& Englebrick, L. (2005). That might work in the suburbs but ... PBS in the urban school. Paper presented at the Second International Conference on Positive Behavior Support. Tampa, Florida.

McMaster, K. L., Fuchs, D., Fuchs, L., \& Compton, D. L. (2005). Responding to non-responders: An experimental field trial of identification and intervention methods. Exceptional Children, 7l, 445-463.

Mendez, L. M. R., \& Knoff, H. M. (2003). Who gets suspended from school and why: A demographic analysis of schools and disciplinary infractions in a large school district. Education and Treatment of Children, 26, 30-51.

Nelson, J. R., Martella, R. M., \& Marchand-Martella, N. (2002). Maximizing student learning: The effects of a comprehensive school-based program for preventing problem behaviors. Journal of Emotional and Behavioral Disorders, 10, 136-148.

Norris, J. A. (2003). Looking at classroom management through a social and emotional learning lens. Theory into Practice, 42, 313-318.

Obiakor, F., \& Utley, C. (2003). Fradulent multiculturalism re- duces the goodness of general and special education. Multiple Voices, 6, v-vi.

Public Agenda. (2004). Teacher interrupted: Do discipline policies in today's public schools foster the common good? Retrieved November 28, 2005, from http://www.publicagenda. org.

Putnam, R. F., Handler, M. W., \& Luiselli, J. K. (2003). Positive schools: A behavioral consultation, intervention, and prevention approach to student discipline. Psychiatric Services, 54,1039

Rollins, S. A., Kaiser-Urley, C., Potts, I., \& Creason, A. H. (2003). A school-based violence prevention model for at risk eighth grade youth. Psychology in the Schools, 40, 403-416.

Sailor, W., \& McCart, A. (2004). Creating a unified system integrating general and special education for the benefit of all students [Video]. Produced by forum on education. This video features the School-wide Applications Model (SAM) and Positive Behavior Support (PBS) at White Church Elementary School in Kansas City, Kansas. Can be purchased from www.forumoneducation.org.

Sailor, W., \& Roger, B. (2003). SAMAN an instrument for the analysis of critical features of the Schoolwide Applications Model (SAM). Unpublished research instrument.

Sailor, W., \& Roger, B. (2005). Rethinking inclusion: Schoolwide applications. Phi Delta Kappan, 7, 503-509.

Skiba, R. \& Peterson, R. (2003). Teaching the social curriculum: School discipline as instruction. Preventing School Failure, 4, 66-73.

Tabachnick, B. G., \& Fidell, L. S. (2001). Using multivariate statistics (4th ed., pp. 111-176). New York: Harper Collins College Publishers, Inc.

Troyan, B. E. (2003). The silent treatment: Perpetual in-school suspension and the education rights of students. Texas Law Review, 81, 1637-1670.

Utley, C. A., \& Sailor, W. (2002). Positive behavior support and urban school improvement: A Special Section of the Journal of Positive Behavior Interventions [Guest editorial]. Journal of Positive Behavior Interventions, 4, 195.

Van Zant, S., \& Martucci, M. (2002). A community affair. Leadership, 31, 34-35.

Received: January 2, 2006

Final Acceptance: March 3, 2006

Editor in Charge: Linda Bambara 


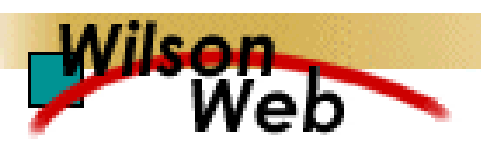

\section{COPYRIGHT INFORMATION}

TITLE: Anchoring Schoolwide Positive Behavior Support in Structural School Ref

SOURCE: Research and Practice for Persons with Severe Disabilities 31 no1 Spr 2006

PAGE(S): $18-30$

WN: 0610507516006

The magazine publisher is the copyright holder of this articleand it is reproduced with permission. Further reproduction of this article in violation of the copyright is prohibited.

Copyright 1982-2006 The H.W. Wilson Company. All rights reserved. 